\title{
Barrier-to-autointegration factor 1: A novel biomarker for gastric cancer
}

\author{
JUNJUN LI ${ }^{1}$, BINGBING HU ${ }^{2}$, LEI FANG ${ }^{3}$, YANG GAO ${ }^{1}$, SHUAI SHI $^{3}$, \\ HAOYU HE ${ }^{1}$, XIAOMEI LIU ${ }^{1}$ and CAIJUN YUAN ${ }^{1}$ \\ ${ }^{1}$ Department of Oncology, The First Affiliated Hospital of Jinzhou Medical University, Jinzhou, Liaoning 121000; \\ ${ }^{2}$ Department of Infectious Diseases, The Third Affiliated Hospital of Xinxiang Medical University, Xinxiang, Henan 453000; \\ ${ }^{3}$ Department of Pathology and Pathophysiology, Jinzhou Medical University, Jinzhou, Liaoning 121001, P.R. China
}

Received November 23, 2017; Accepted June 26, 2018

DOI: $10.3892 / \mathrm{ol} .2018 .9432$

\begin{abstract}
China is a country with a high incidence of gastric cancer (GC), where the GC incidence and the resultant mortality rates account for $50 \%$ of those worldwide. Surgical resection remains the primary treatment for GC. However, postoperative patients have a poor prognosis as the majority of patients present with metastases at the time of diagnosis. Therefore, the identification of novel treatment targets is required. The present study aimed to determine the effects of barrier-to-autointegration factor 1 (BANF1) on the clinical features and prognosis of GC, which may aid in discovering a novel tumor diagnostic biomarker and treatment target. The BANF1 gene expression profiles for normal and gastric tumor tissues were downloaded from the Gene Expression Omnibus GSE54129 data set to analyse the expression of BANF1 at the mRNA levels. Then, online survival analysis was performed using the GC database with the Kaplan-Meier Plotter (http://kmplot.com/analysis/) data. To examine the association between BANF1 and clinical features and prognosis, 132 postoperative GC pathological specimens were collected for immunohistochemical analyses. In the GSE54129 data sets, BANF1 expression at the mRNA level was significantly higher in the tumor tissue compared with that in the normal tissue. The same result was obtained in following the immunohistochemical analyses. In addition, BANF1 expression was associated with the patient age, tumor differentiation and infiltration depth. The survival time of BANF1 high-expression patients was shorter compared with that of the low-expression patients, and tumor differentiation status and tumor node metastasis
\end{abstract}

Correspondence to: Professor Caijun Yuan, Department of Oncology, The First Affiliated Hospital of Jinzhou Medical University, 2 The Fifth Section of Renmin Street, Jinzhou, Liaoning 121000, P.R. China

E-mail: 2151208698@qq.com

Key words: barrier-to-autointegration factor 1, gastric cancer, biomarker, clinical features, prognosis stage were independent prognostic factors of the overall survival of patients with GC. The results of the present study suggest that BANF1 is associated with the clinical features and prognosis of GC. It may be a novel indicator of tumor prognosis and a potential therapeutic target for GC.

\section{Introduction}

Of the worldwide population of patients with gastric cancer (GC), $42 \%$ of the men and $19 \%$ of the women are Chinese, and the number of patients suffering from GC has increased in recent years $(1,2)$. Although significant progress has been made in the comprehensive treatment with surgery, the prognosis for postoperative patients with GC remains poor (3). A detailed understanding of GC occurrence and development, and the factors that influence its prognosis are required.

The barrier-to-autointegration factor 1 (BANF1) family of proteins has a variety of functions associated with the maintenance of the intact cellular genome (4). BANF1 is an $\sim 10-\mathrm{kDa}$, highly conserved DNA-binding protein that forms homodimers. It was first identified during the combination of a retrovirus and host, promoting the fusion of retroviruses and target genes in vitro (5). As an important part of the lamina, BANF1 has essential interactions with numerous cellular proteins, including transcription factors and DNA damage repair proteins $(6,7)$. It regulates gene expression, participates in the formation of karyotin structures and is associated with cell mitosis (8).

In recent years, with the advent of microarray technology, novel ideas and insights into the diagnosis and treatment of tumors have been proposed (9). To understand the effect of BANF1 on GC progression, its mRNA and protein expression levels in the gastric tumor tissue were compared with that in adjacent non-tumorous tissue. BANF1 expression was demonstrated to be upregulated in patients with GC. In addition, a high expression of BANF1 was identified as a poor prognostic factor. Furthermore, BANF1 expression correlated with patient age, tumor differentiation and infiltration depth. Therefore, BANF1 may be an oncogene. The results of the present study may aid in developing a reference in prognostic evaluation of patients with GC. 


\section{Materials and methods}

Data source. The microarray profiles of GC were extracted from the Gene Expression Omnibus (GEO, http://www.ncbi. nlm.nih.gov/geo/) database under the accession number of GSE54129. A total of 132 specimens, including 21 gene chips from adjacent non-tumorous tissue and 111 gene chips from tissues of GC patients, were available for the analysis by GEO2R. The GEO data was passed through quality control and homogeneous processing as previously described (9). A total of 876 cases of gastric cancer used for prognostic analysis were derived from the Kaplan-Meier Plotter database. Survival analysis was performed using the GC database with the Kaplan-Meier (K-M) estimator data. For comparison, the data group $(n=876)$ was segmented into the high $(n=604)$ and low $(\mathrm{n}=272) \mathrm{BANF} 1-$ expression groups with the median as the boundary.

Clinical GC specimen collection.Postoperative specimens were collected between June 2012 and January 2013 from The First Affiliated Hospital of Jinzhou Medical University (Jinzhou, China), which included 23 normal and 118 tumorous tissues. Specimens were placed in $10 \%$ neutral buffered formalin for $24 \mathrm{~h}$ at room temperature (RT) and then embedded in a paraffin wax block for storage. No patients received any other treatment prior to surgery. Table I lists the clinicopathological features of all patients. The 8th edition tumor node metastasis (TNM) staging system of the Union for International Cancer Control was the standard for tumor staging (10). The present study was approved by the Ethics Committees of the First Affiliated Hospital of Jinzhou Medical University. Written informed consent was obtained from all patients.

Cell culture. The SGC-7901 and MNK-45 GC cell lines (Hangzhou Baisi Biotechnology Co., Ltd., Hangzhou, China) were grown in RPMI-1640 (HyClone; GE Healthcare, Logan, UT, USA) supplemented with $10 \%$ fetal bovine serum (Gibco; Thermo Fisher Scientific, Inc., Waltham, MA, USA), $100 \mathrm{U} / \mathrm{ml}$ penicillin and $100 \mu \mathrm{g} / \mathrm{ml}$ streptomycin, at $37^{\circ} \mathrm{C}$ in $5 \% \mathrm{CO}_{2}$.

Western blot analysis. Cells were lysed in RIPA lysis buffer (cat. no. WLA016a; Wanleibio Co., Ltd., Shenyang, China). Protein quantification was performed using the Coomassie Brilliant Blue method. Subsequently, $30 \mu \mathrm{g}$ protein/lane were separated by $12 \%$ SDS-PAGE and transferred to a polyvinylidene fluoride membrane. The membrane was blocked with 5\% skim milk in Tris-buffered saline with Tween 20 (TBST, $10 \mathrm{mM}$ Tris- $\mathrm{HCl}, 150 \mathrm{mM} \mathrm{NaCl}, 0.1 \%$ Tween 20) for $1 \mathrm{~h}$ at $\mathrm{RT}$, and then incubated with the rabbit monoclonal anti-BANF1 (cat. no. McAb129184; 1:500; Abcam, Cambridge, UK) and rabbit anti-GAPDH (cat. no. WL01114; 1:2,000; Wanleibio Co., Ltd) antibodies overnight at $4^{\circ} \mathrm{C}$. The membranes were washed with TBST and incubated with the goat anti-rabbit IgG secondary antibody (cat. no. WLA023a; 1:5,000; Wanleibio Co., Ltd. Shenyang, China). The bands were visualized with a LAS4010 imager (GE Healthcare Life Sciences, Little Chalfont, UK) using ECL-Plus detection reagent (Santa Cruz Biotechnology, Inc., Dallas, TX, USA). The densitometric quantification of protein bands was performed with GAPDH as a control using ImageJ software version 1.8.0 (National Institutes of Health, Bethesda, MD, USA). To validate the specificity of anti-BANF1 antibodies, rabbit anti-BANF1-peptide-specific antibodies (cat. no. 4019P; 1:100; ProSci Inc., Poway, CA, USA) were used against the 15 amino acids near the carboxy-terminus of human BANF1. After the diluted anti-BANF1 antibodies were preincubated with (+) and without (-) $0.5 \mathrm{mM}$ anti-BANF1-peptide-specific antibodies for $2 \mathrm{~h}$ at RT, they were used to determine BANF1 expression in SGC-7901 and MNK-45 GC cells (11). The aforementioned western blotting protocol was performed in the same way following this incubation.

Immunohistochemistry. Tissue specimens were cut into successive $4 \mu \mathrm{m}$-thick sections. Then, antigen retrieval was performed by heating the specimens using the pressure cooker antigen repairing method at $120^{\circ} \mathrm{C}$, followed by washing with xylene and gradual rehydration with a descending ethanol series. Endogenous peroxidase activity in the specimens was neutralized via incubation with $3 \%$ hydrogen peroxide for $5 \mathrm{~min}$ at room temperature. Subsequently, the specimens were incubated in $5 \%$ bovine serum albumin (cat. no. A8020; Beijing Solarbio Science \& Technology Co., Ltd., Beijing, China) for $30 \mathrm{~min}$ at RT to block nonspecific binding. Then, the tissues were incubated with rabbit monoclonal anti-BANF1 antibody (1:100) overnight at $4^{\circ} \mathrm{C}$. Following incubation with the horseradish peroxidase-conjugated goat anti-rabbit IgG secondary antibodies (cat. no. WLA023a; 1:500; Wanleibio Co., Ltd.) for $1 \mathrm{~h}$ at RT, all sections were visualized using 3,3'-diaminobenzidine, and the slides were counterstained with haematoxylin (cat. no. WLA051a; Wanleibio Co., Ltd.) for $1 \mathrm{~min}$ at RT $(1,2)$. The coverslips were then mounted with anti-fade mounting medium and observed under a microscope (magnification x200; Olympus DP73; Japan).

Staining intensity score. The BANF1 expression-intensity scores were determined by two independent observers blinded to the clinicopathological data of patients. In order to calculate the percentage of BANF1-positive cells, 100 cells were randomly selected and counted in five representative fields of each section. The positive expression area was counted as follows: $<5 \%$, score of $0 ;<30 \%$, score of $1 ; 30-70 \%$, score of 2 ; and $>70 \%$, score of 3 . The staining intensity score was graded as follows: Colourless, 0 ; weak, 1; intermediate, 2; and strong, 3 . The positive expression area and staining intensity scores were multiplied (2).

Statistical analysis. All data were analysed with the SPSS 20.0 software program (IBM Corp., Armonk, NY, USA). Results were expressed as the mean \pm standard deviation. Student's t-tests were performed to evaluate the differences in BANF1 mRNA expression between the gastric tumor and normal tissues. The Spearman's rank correlation coefficient test was used to analyze the correlation between BANF1 expression and clinicopathological features. The Mann-Whitney U-test was used to calculate the statistical significance. Survival curves were derived using the K-M estimator method and compared using the log-rank test. Cox's proportional hazards model was used to analyze the effect of clinicopathological 
Table I. Association between BANF1 expression and clinicopathological features.

BANF1 expression

\begin{tabular}{|c|c|c|c|c|c|c|c|}
\hline \multirow{2}{*}{ Clinicopathological features } & \multirow[b]{2}{*}{ No. } & \\
\hline & & - & + & ++ & +++ & PR (\%) & P-value \\
\hline Sex & & & & & & & 0.260 \\
\hline Male & 76 & 3 & 7 & 26 & 40 & 96.1 & \\
\hline Female & 42 & 0 & 1 & 16 & 25 & 100.0 & \\
\hline Age, years & & & & & & & $0.001^{\mathrm{a}}$ \\
\hline$\geq 60$ & 60 & 2 & 6 & 29 & 23 & 96.7 & \\
\hline$<60$ & 58 & 1 & 2 & 13 & 42 & 98.3 & \\
\hline Tumor size, $\mathrm{cm}$ & & & & & & & 0.648 \\
\hline$\geq 5$ & 51 & 1 & 2 & 21 & 27 & 98.0 & \\
\hline$<5$ & 67 & 2 & 6 & 21 & 38 & 97.0 & \\
\hline Differentiation & & & & & & & $0.000^{\mathrm{a}}$ \\
\hline Poor & 57 & 0 & 0 & 3 & 54 & 100.0 & \\
\hline Moderate & 50 & 1 & 4 & 37 & 8 & 98.0 & \\
\hline Well & 7 & 2 & 4 & 1 & 0 & 71.4 & \\
\hline Infiltration depth & & & & & & & $0.011^{\mathrm{a}}$ \\
\hline $\mathrm{T} 1 / \mathrm{T} 2$ & 28 & 2 & 5 & 10 & 11 & 92.9 & \\
\hline $\mathrm{T} 3 / \mathrm{T} 4$ & 90 & 1 & 3 & 32 & 54 & 98.9 & \\
\hline Lymph node metastasis & & & & & & & 0.154 \\
\hline With & 86 & 3 & 6 & 33 & 44 & 96.5 & \\
\hline Without & 32 & 0 & 2 & 9 & 21 & 100.0 & \\
\hline Distant metastasis & & & & & & & 0.214 \\
\hline M0 & 116 & 3 & 8 & 42 & 63 & 97.4 & \\
\hline M1 & 2 & 0 & 0 & 0 & 2 & 100.0 & \\
\hline TNM staging & & & & & & & 0.207 \\
\hline I and II & 37 & 2 & 6 & 10 & 19 & 94.6 & \\
\hline III and IV & 81 & 1 & 2 & 32 & 46 & 98.8 & \\
\hline
\end{tabular}

${ }^{\text {a }} \mathrm{P}<0.05$. PR, positive rate; BANF1, barrier-to-autointegration factor 1; TNM, tumor node metastasis.

parameters on patient survival. $\mathrm{P}<0.05$ was considered to indicate a statistically significant difference.

\section{Results}

High expression of BANF1 mRNA in GC tissues. In the GSE54129 data sets, BANF1 expression in the gastric tumor tissues was identified to be significantly higher compared with in the adjacent non-tumorous tissues (Fig. 1), as demonstrated by statistical parameters for the BANF1 gene expression profiles in Table II $\left(\mathrm{P}=1.50 \times 10^{-87}\right)$.

Expression of BANF1 in GC cells. After the diluted anti-BANF1 antibodies were preincubated with the anti-BANF1-peptide-specific antibodies, the latter were used for western blotting. Examination of total extracts of SGC-7901 and MNK-45 GC cells by immunoblotting revealed that the antibodies specifically recognized a $10-\mathrm{kDa}$ protein (Fig. 2, lanes 1 and 2), which was not present at the same positions in the lanes with anti-BANF1-peptide-specific antibody preincubation (Fig. 2, lanes 3 and 4). This indicates that

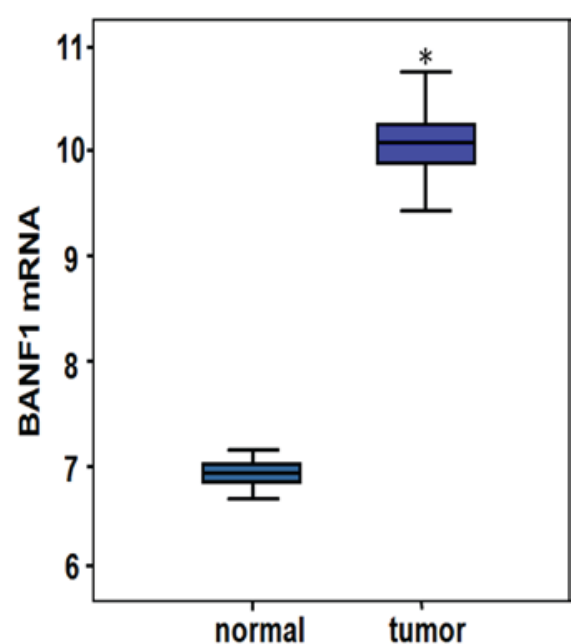

Figure 1. mRNA expression of BANF1 in the GSE54129 data sets. The gastric cancer microarray profiles were extracted from the Gene Expression Omnibus database under the accession number of GSE54129. BANF1 expression at the mRNA level in tumor tissues (10.05825) was significantly higher compared with that in normal tissues $(6.93204)\left(\mathrm{P}=1.50 \times 10^{-87}\right) .{ }^{*} \mathrm{P}<0.05$. BANF1, barrier-to-autointegration factor 1 . 
Table II. Statistical parameters of BANF1 gene expression profiles.

\begin{tabular}{|c|c|c|c|c|c|c|c|}
\hline Gene name & ID & Normal mean & Tumor mean & $\log F C$ & $\mathrm{t}$ & P-value & Adjust P-value \\
\hline BANF1 & 210125_s_at & 6.93204 & 10.05825 & 3.126 & 49.7 & $1.50 \times 10-87^{\mathrm{a}}$ & $8.20 \times 10-83^{a}$ \\
\hline
\end{tabular}

${ }^{\mathrm{a}} \mathrm{P}<0.05$. BANF1, barrier-to-autointegration factor $1 ; \mathrm{FC}$, fold change.

BANF1 protein is expressed in SGC-7901 and MNK-45 GC cells and the anti-BANF1 antibody can specifically recognize the $10 \mathrm{kDa}$ BANF1 protein.

Difference in BANF1 protein expression between the normal and gastric tumor tissues. The intensity of BANF1 expression in the nucleus of GC cells varied (Fig. 3). The total of $118 \mathrm{GC}$ tissues included three cases of negative BANF1 expression, eight weakly positive $(+)$ samples, 42 moderately positive $(++)$ samples and 65 strongly positive $(+++)$ samples. By contrast, negative (-) and weakly positive (+) BANF1 staining was detected in 18 samples and five samples of 23 normal tissues, respectively, while no moderately positive or strongly positive staining was detected. The protein expression of BANF1 in GC specimens was significantly higher compared with that in normal tissues $(\mathrm{P}<0.001$; Table III).

BANF1 expression is associated with patient age, and the degree of GC differentiation and depth of invasion. The immunohistochemistry results are summarized in Table I. The rates of positive BANF1 expression in GC tissues with low, medium and high differentiation statuses were 100, 98 and $71.4 \%$, respectively. The BANF1 expression in poorly differentiated GC tissues was significantly higher compared with that in moderately and highly differentiated tissues, and was associated with the differentiation degree of tumors $(\mathrm{P}<0.001)$. In addition, BANF1 expression correlated with the patient age $(\mathrm{P}=0.001)$ and tumor infiltration depth $(\mathrm{P}=0.011)$.

Effect of BANF1 expression on the overall survival (OS) of postoperative patients. Online survival analysis was performed using the GC database in K-M Plotter, which revealed that the survival times for patients with high BANF1 mRNA expression was significantly reduced compared with that for the low-expression patients [log-rank test, $\mathrm{P}<0.001$; hazard ratio (HR), 2.37; 95\% confidence interval (CI), 1.93-2.92; Fig. 4A]. Subsequently, the K-M estimator method was used to analyze the effect of BANF1 expression on the postoperative overall survival (OS) time of patients, the follow-up period was 150 months, and the mortality was considered as the end point during the follow-up period. The survival curve suggested that the OS of the patients with low BANF1 expression was significantly increased compared with the OS of high expression patients (log-rank test, $\mathrm{P}<0.001$; Fig. 4B). Thus, the level of BANF1 expression may be used as a prognostic indicate for patients with GC. Next, the age, the TNM stage and other clinical features were incorporated into the Cox regression model. It was revealed that the tumor differentiation status and the TNM stage were independent factors affecting the OS of patients with GC (Table IV).
Table III. BANF1 expression in gastric cancer.

\begin{tabular}{lrrrrrrr}
\hline & & \multicolumn{6}{c}{ BANF1 expression } \\
\cline { 3 - 7 } Group & No. & - & + & ++ & +++ & PR (\%) & P-value \\
\hline Normal & 23 & 18 & 5 & 0 & 0 & 21.7 & $<0.001^{\text {a }}$ \\
Cancer & 118 & 3 & 8 & 42 & 65 & 97.5 & \\
\hline
\end{tabular}

${ }^{\mathrm{a}} \mathrm{P}<0.05$. $\mathrm{PR}$, positive rate; $\mathrm{BANF} 1$, barrier-to-autointegration factor 1 .

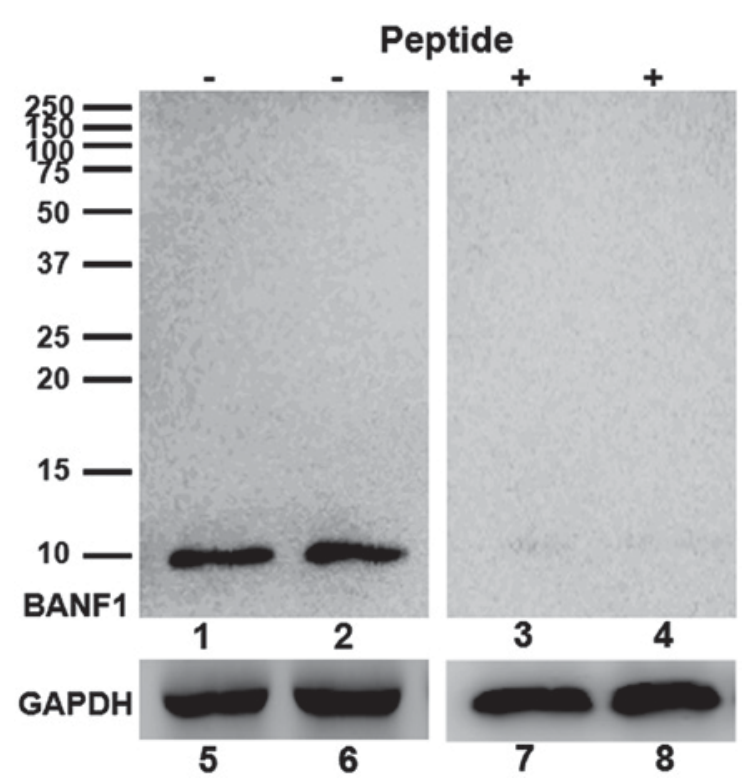

Figure 2. Detection of BANF1 protein in SGC-7901 and MNK-45 gastric cancer cells by western blot analysis. Lanes $1,3,5$ and 7 correspond to total cell extracts of SGC-7901 gastric cancer cells. Lanes 2, 4, 6 and 8 correspond to total cell extracts of MNK-45 gastric cancer cells. The diluted anti-BANF1 antibodies were preincubated with (+) and without (-) $0.5 \mathrm{mM}$ anti-BANF1-peptide-specific antibodies. The positions of the BANF1 proteins are marked at $10 \mathrm{kDa}$ in lanes 1 and 2 , which were not present at the same position in lanes 3 and 4. BANF1, barrier-to-autointegration factor 1.

\section{Discussion}

The five-year survival rates of postoperative patients with GC vary between 15 and $60 \%$, with GC diagnosis and detection lacking effective biomarkers $(1,12)$. Despite the significant advances in the understanding of GC pathogenesis, there is no effective therapy available for GC treatment. Therefore, the identification of effective biomarkers is required to significantly improve the early diagnosis rate and prognosis for patients with GC. 


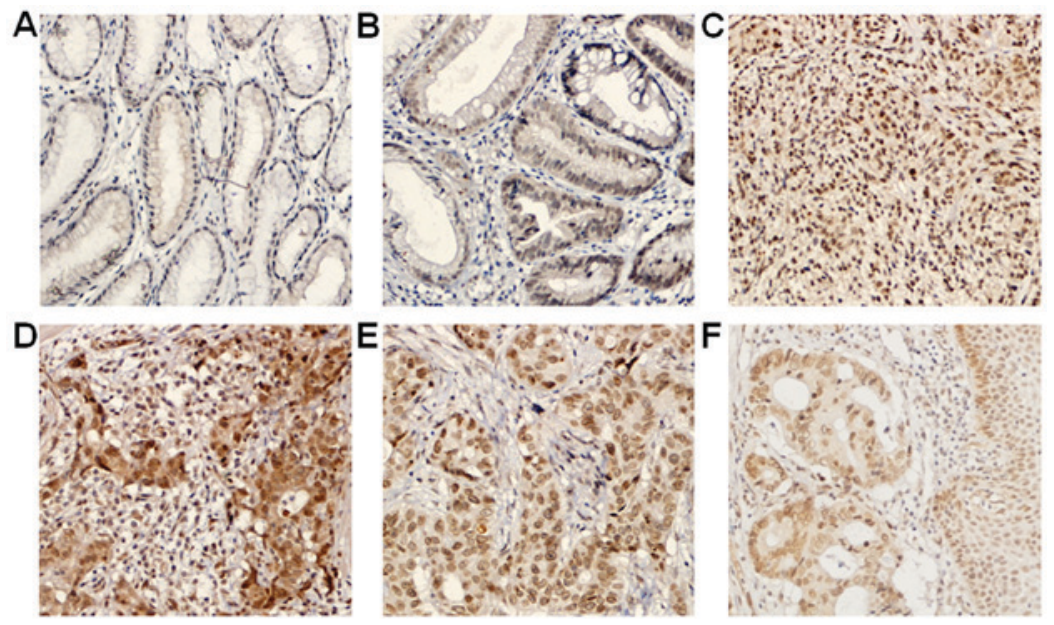

Figure 3. Immunohistochemistry staining of BANF1 in gastric cancer. (A) Normal gastric tissues. (B) Atypical hyperplasia tissues. (C) Gastrointestinal stromal tumor tissues. (D) Poorly differentiated adenocarcinoma. (E) Moderately differentiated adenocarcinoma. (F) Highly differentiated adenocarcinoma. (A) No BANF1 expression (-); (F) weakly stained; (E) moderately positive expression (++) (C) and (D) strongly positive expression (+++) Magnification, x200. BANF1, barrier-to-autointegration factor 1.
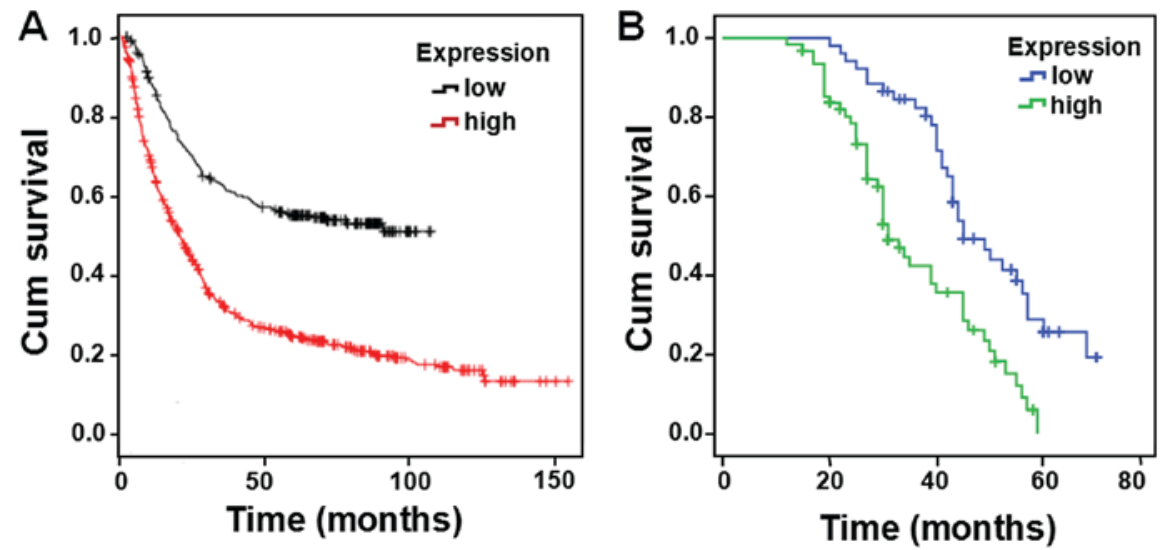

Figure 4. Survival curve for patients with GC patients. (A) The K-M curve of BANF1 mRNA expression from the K-M Plotter data (log-rank test, $\left.\mathrm{P}<1 \times 10^{-16}\right)$. (B) The K-M curve of BANF1 protein expression (log-rank test, $\mathrm{P}<0.001)$. The overall survival of the patients in the low-expression group was significantly improved compared with that of the patients in the high-expression group. BANF1, barrier-to-autointegration factor 1; Cum, cumulative; K-M, Kaplan-Meier.

BANF1 encodes a highly conserved BAF protein consisting of 89 amino acids and binding to double-stranded DNA with high-affinity. It was discovered due to its involvement in the integration of retroviral DNA (13). Regulation of BAF phosphorylation, mediated by cell or virus, regulates numerous cellular activities, including protein dimerization, its binding to DNA, and subcellular localization of the protein (14-16). Additionally, BAF participates in karyomitosis, karyon assembly, karyoplasm regulation and the DNA damage response (17). As the first protein that is recruited to the core area of karyolemma, the role of BAF in mitosis is important. Once BAF is located at the core of chromatin, other karyotheca anchoring and membrane-spanning proteins are recruited to complete the nuclear membrane reformation, which is a key step in cell mitosis $(18,19)$. Previous studies have demonstrated that the absence of BAF or the blockage of its phosphorylation results in abnormal morphological abnormalities of the caryotheca (13). This causes aberrant nuclear architecture and disrupts normal cell mitosis process (20). Abnormal mitosis may cause chromosomal instability, which is considered a characteristic change in malignant tumor cells (21).

BAF is able to positively or negatively regulate cell activities, although the specific mechanisms remain unclear. At the early stages of Caenorhabditis elegans embryogenesis, BAF regulates seam cell fusion by suppressing the expression of epithelial fusion failure-1-fused protein and the development of germ cells (22). It has been reported that BAF inhibits transcription in vaccinia virus deficiency in the viral B1 kinase $(23,24)$. Activation of BANF1 may inhibit skin inflammation in psoriatic lesions by inactivation of S100A9 and c-Jun, but it may also promote keratinocyte proliferation (5). A coding mutation of the BANF1 alanine-12 to threonine was reported to be associated with BANF1-protein instability and abnormalities of the caryotheca, which has been confirmed as the hereditary fundamental of Néstor-Guillermo Progeria syndrome (NGPS) (25). The disruption of the interaction between Prelamin A and BAF may be the cause of NGPS (26). In addition, certain studies have reported that BANF1 
Table IV. Cox multivariate regression analysis of the association between the clinical factors and overall survival.

\begin{tabular}{|c|c|c|}
\hline $\begin{array}{l}\text { Clinicopathological } \\
\text { factors }\end{array}$ & Relative risk $(95 \% \mathrm{CI})$ & P-value \\
\hline $\begin{array}{l}\text { BANF1 } \\
\text { Negative (-) } \\
\text { Positive (+) }\end{array}$ & $0.686(0.305-1.542)$ & 0.362 \\
\hline $\begin{array}{l}\text { Age, years } \\
\geq 60 \\
<60\end{array}$ & $0.749(0.457-1.227)$ & 0.25 \\
\hline $\begin{array}{l}\text { Sex } \\
\text { Male } \\
\text { Female }\end{array}$ & $0.899(0.550-1.470)$ & 0.672 \\
\hline $\begin{array}{l}\text { Tumor size, cm } \\
\geq 5 \\
<5\end{array}$ & $1.578(0.948-2.628)$ & 0.079 \\
\hline $\begin{array}{l}\text { Differentiation } \\
\text { Poor }\end{array}$ & & \\
\hline $\begin{array}{l}\text { Moderate } \\
\text { Poor } \\
\text { Well }\end{array}$ & $\begin{array}{l}7.495(1.448-38.809) \\
4.989(1.129-22.052)\end{array}$ & $\begin{array}{l}0.016^{\mathrm{a}} \\
0.034^{\mathrm{a}}\end{array}$ \\
\hline $\begin{array}{l}\text { Infiltration depth } \\
\text { T1/T2 } \\
\text { T3/T4 }\end{array}$ & $0.872(0.402-1.889)$ & 0.728 \\
\hline $\begin{array}{l}\text { Lymph node metastasis } \\
\text { With } \\
\text { Without }\end{array}$ & $0.913(0.479-1.742)$ & 0.783 \\
\hline $\begin{array}{l}\text { TNM staging } \\
\text { Phase I and II } \\
\text { Phase III and IV }\end{array}$ & $0.230(0.109-0.485)$ & $<0.001^{\mathrm{a}}$ \\
\hline
\end{tabular}

${ }^{\mathrm{a}} \mathrm{P}<0.05$. CI, confidence interval; BANF1, barrier-to-autointegration factor 1; TNM, tumor node metastasis.

expression is increased in breast and oesophageal cancer, and is associated with the poor prognosis of patients $(27,28)$. Furthermore, its role is essential in regulating the S-phase process, stem cell self-renewal, and differentiation and proliferation of keratinocytes $(5,29)$.

Targeted therapy and individualized tumor treatment are directed against specific gene mutations and proteins. Based on the notion of tumor therapy treatment, it is essential to identify suitable oncogenes to develop small molecules or monoclonal antibodies to control the disease. BANF1 has been demonstrated to be a target for the treatment of tumors with a specialized inhibitor aimed at BAF phosphorylation mediated by vaccinia related kinase 1 , which blocks cell cycle progression in tumor cells by interfering with the caryomitotic phase (30).

In the present study, the expression level of BANF1 was demonstrated to be significantly increased in GC tissues, and was inversely correlated with the patient age, tumor differentiation status and infiltration depth. Furthermore, the survival curve analysis revealed that the prognosis for patients with high BANF1 expression was poor at the mRNA and protein levels. To further investigate the association between the clinical characteristics and prognosis, Cox regression analysis was performed. The results suggested that tumor differentiation status and TNM stage were independent risk factors affecting the OS of patients with GC. The HR of BANF1 was 0.686 (95\% CI, 0.305-1.542; $\mathrm{P}=0.362$ ) in the Cox regression analysis, but BANF1 significantly impacts poor survival of $\mathrm{GC}$ in the $\mathrm{K}-\mathrm{M}$ analysis $(\log -\mathrm{rank} \mathrm{P}<0.001)$. This indicates that BANF1 has an impact on prognosis together with other factors, but is not an independent prognostic factor by itself. A limitation of the present study was that the BANF1 protein levels in the tissues from patients with GC were only detected by immunohistochemistry, and that western blot analysis is required to support the immunohistochemistry results.

In summary, BANF1 expression was upregulated in clinical GC tissues, and was associated with the tumor age, infiltration depth and differentiation. Additionally, the results of the present study confirmed that BANF1 closely correlates with adverse outcomes in GC patients undergoing surgery. Taken together, the present study is the first to propose that high BANF1 expression may be used as a novel indicator of poor prognosis or as a therapeutic target for patients with GC.

\section{Acknowledgements}

Not applicable.

\section{Funding}

The present study was supported by the Liaoning Province Science and Technology Project (grant no. 2010010280-401).

\section{Availability of data and materials}

The datasets generated and/or analyzed during the present study are available in the GEO repository (http://www.ncbi.nlm.nih. gov/geo/) and the Kaplan-Meier Plotter database (http://kmplot. com/analysis/index.php? $\mathrm{p}=$ service $\&$ cancer $=$ gastric).

\section{Authors' contributions}

JL, BH, LF, YG, SS and HH performed the experiments and analyzed the data. JL, LF, XL and CY designed the study and co-wrote the manuscript. JL, YG, LF and HH were involved in revising the manuscript. All the authors have read and approved the final version of the manuscript.

\section{Ethics approval and consent to participate}

The present study was approved by the Ethics Committees of the First Affiliated Hospital of Jinzhou Medical University. Written informed consent was obtained from all patients.

\section{Patient consent for publication}

Written informed consent was obtained from all patients regarding the publication of the data and associated images. 


\section{Competing interests}

The authors declare that they have no competing interests.

\section{References}

1. Bray F, Jemal A, Grey N, Ferlay J and Forman D: Global cancer transitions according to the human development index (2008-2030): A population-based study. Lancet Oncol 13: 790-801, 2012.

2. Chu D, Zhu S, Li J, Ji G, Wang W, Wu G and Zheng J: CD147 expression in human gastric cancer is associated with tumor recurrence and prognosis. PLoS One 9: e101027, 2014.

3. Sun J, Jiang J, Lu K, Chen Q, Tao D and Chen Z: Therapeutic potential of ADAM17 modulation in gastric cancer through regulation of the EGFR and TNF- $\alpha$ signalling pathways. Mol Cell Biochem 426: 17-26, 2017.

4. Shen Q, Eun JW, Lee K, Kim HS, Yang HD, Kim SY, Lee EK, Kim T, Kang K, Kim S, et al: Barrier to autointegration factor 1, procollagen-lysine, 2-oxoglutarate 5-dioxygenase 3, and splicing factor $3 \mathrm{~b}$ subunit 4 as early-stage cancer decision markers and drivers of hepatocellular carcinoma. Hepatology 67: 1360-1377, 2018.

5. Takama H, Sugiura K, Ogawa Y, Muro Y and Akiyama M: Possible roles of barrier-to-autointegration factor 1 in regulation of keratinocyte differentiation and proliferation. J Dermatol Sci 71: 100-106, 2013.

6. Mekhail K and Moazed D: The nuclear envelope in genome organization, expression and stability. Nat Rev Mol Cell Biol 11: 317-328, 2010.

7. Hutchison CJ: Lamins: Building blocks or regulators of gene expression? Nat Rev Mol Cell Biol 3: 848-858, 2002.

8. Brachner A, Braun J, Ghodgaonkar M, Castor D, Zlopasa L, Ehrlich V, Jiricny J, Gotzmann J, Knasmüller S and Foisner R: The endonuclease Ankle1 requires its LEM and GIY-YIG motifs for DNA cleavage in vivo. J Cell Sci 125: 1048-1057, 2012.

9. Pastorino U: Lung cancer screening. Br J Cancer 102: 1681-1686, 2010.

10. Liu JY, Peng CW, Yang XJ, Huang CQ and Li Y: The prognosis role of AJCC/UICC 8th edition staging system in gastric cancer, a retrospective analysis. Am J Transl Res 10: 292-303, 2018.

11. Furukawa K: LAP2 binding protein 1 (L2BP1/BAF) is a candidate mediator of LAP2-chromatin interaction. J Cell Sci 112: 2485-2492, 1999.

12. Sotgia F and Lisanti MP: Mitochondrial biomarkers predict tumor progression and poor overall survival in gastric cancers: Companion diagnostics for personalized medicine. Oncotarget 8: 67117-67128, 2017.

13. Molitor TP and Traktman P: Depletion of the protein kinase VRK1 disrupts nuclear envelope morphology and leads to BAF retention on mitotic chromosomes. Mol Biol Cell 25: 891-903, 2014.

14. Wiebe MS and Jamin A: The barrier to autointegration factor: Interlocking antiviral defense with genome maintenance. J Virol 90: 3806-3809, 2016

15. Snyers L, Erhart R, Laffer S, Pusch O, Weipoltshammer K and Schöfer C: LEM4/ANKLE-2 deficiency impairs post-mitotic re-localization of BAF, LAP $2 \alpha$ and LaminA to the nucleus, causes nuclear envelope instability in telophase and leads to hyperploidy in HeLa cells. Eur J Cell Biol 97: 63-74, 2018.

16. Chou W, Ngo T and Gershon PD: An overview of the vaccinia virus infectome: A survey of the proteins of the poxvirus-infected cell. J Virol 86: 1487-1499, 2012.
17. Samwer M, Schneider MWG, Hoefler R, Schmalhorst PS, Jude JG, Zuber J and Gerlich DW: DNA cross-bridging shapes a single nucleus from a set of mitotic chromosomes. Cell 170: 956-972, 2017

18. Haraguchi T, Kojidani T, Koujin T, Shimi T, Osakada H, Mori C, Yamamoto A and Hiraoka Y: Live cell imaging and electron microscopy reveal dynamic processes of BAF-directed nuclear envelope assembly. J Cell Sci 121: 2540-2554, 2008.

19. Kim SH, Lyu HN, Kim YS, Jeon YH, Kim W, Kim S, Lim JK, Lee HW, Baek NI, Choi KY, et al: Brazilin isolated from caesalpinia sappan suppresses nuclear envelope reassembly by inhibiting barrier-to-autointegration factor phosphorylation. J Pharmacol Exp Ther 352: 175-184, 2015.

20. Qi R, Xu N, Wang G, Ren H, Li S, Lei J, Lin Q, Wang L, Gu X and Zhang $\mathrm{H}$ : The lamin-A/C-LAP2 $\alpha-\mathrm{BAF} 1$ protein complex regulates mitotic spindle assembly and positioning. J Cell Sci 128: 2830-2841, 2015.

21. Zhuang $X$, Semenova E, Maric D and Craigie R: Dephosphorylation of barrier-to-autointegration factor by protein phosphatase 4 and its role in cell mitosis. J Biol Chem 289: 1119-1127, 2014.

22. Margalit A, Neufeld E, Feinstein N, Wilson KL, Podbilewicz B and Gruenbaum Y: Barrier toautointegration factor blocks premature cell fusion and maintains adult muscle integrity in C. elegans. J Cell Biol 178: 661-673, 2007.

23. Zheng R, Ghirlando R, Lee MS, Mizuuchi K, Krause M and Craigie R: Barrier-to-autointegration factor (BAF) bridges DNA in a discrete, higher-order nucleoprotein complex. Proc Natl Acad Sci USA 97: 8997-9002, 2000.

24. Ibrahim N, Wicklund A, Jamin A and Wiebe MS: Barrier to autointegration factor (BAF) inhibits vaccinia virus intermediate transcription in the absence of the viral B1 kinase. Virology 444: 363-373, 2013.

25. Paquet N, Box JK, Ashton NW, Suraweera A, Croft LV, Urquhart AJ, Bolderson E, Zhang SD, O'Byrne KJ and Richard DJ: Néstor-guillermo progeria syndrome: A biochemical insight into barrier-to-autointegration factor 1, alanine 12 threonine mutation. BMC Mol Biol 15: 27, 2014.

26. Loi M, Cenni V, Duchi S, Squarzoni S, Lopez-Otin C, Foisner R, Lattanzi $\mathrm{G}$ and Capanni C: Barrier-to-autointegration factor (BAF) involvement in prelamin A-related chromatin organization changes. Oncotarget 7: 15662-15677, 2015.

27. Li J, Wang T, Pei L, Jing J, Hu W, Sun T and Liu H: Expression of VRK1 and the downstream gene BANF1 in esophageal cancer. Biomed Pharmacother 89: 1086-1091, 2017.

28. Lai TC, Chou HC, Chen YW, Lee TR, Chan HT, Shen HH, Lee WT, Lin ST, Lu YC, Wu CL and Chan HL: Secretomic and proteomic analysis of potential breast cancer markers by two-dimensional differential gel electrophoresis. J Proteome Res 9: 1302-1322, 2010.

29. Cox JL, Mallanna SK, Ormsbee BD, Desler M, Wiebe MS and Rizzino A: Banf1 is required to maintain the self-renewal of both mouse and human embryonic stem cells. J Cell Sci 124: 2654-2665, 2011

30. Kim W, Lyu HN, Kwon HS, Kim YS, Lee KH, Kim DY, Chakraborty G, Choi KY, Yoon HS and Kim KT: Obtusilactone B from Machilus Thunbergii targets barrier-to-autointegration factor to treat cancer. Mol Pharmacol 83: 367-376, 2013.

This work is licensed under a Creative Commons Attribution-NonCommercial-NoDerivatives 4.0 International (CC BY-NC-ND 4.0) License. 